This item is the archived peer-reviewed author-version of:

\title{
No signs of thermal acclimation of heterotrophic respiration from peat soils exposed to different water levels
}

\section{Reference:}

Vicca Sara, Fivez Lise, Kockelbergh Fred, van Pelt Dimitri, Segers Jan J.R., Meire Patrick, Ceulemans Reinhart, Janssens Ivan.- No signs of thermal acclimation of heterotrophic respiration from peat soils exposed to different water levels Soil biology and biochemistry - ISSN 0038-0717 - 41:9(2009), p. 2014-2016

Full text (Publishers DOI): http://dx.doi.org/doi:10.1016/j.soilbio.2009.07.007

Handle: http://hdl.handle.net/10067/776580151162165141 


\section{Short communication:}

2 No signs of thermal acclimation of heterotrophic respiration from peat

\section{3 soils exposed to different water levels}

5 Sara Vicca ${ }^{1 *}$, Lise Fivez ${ }^{2}$, Fred Kockelbergh ${ }^{1}$, Dimitri Van Pelt ${ }^{2}$, Jan J.R. Segers ${ }^{1}$,

6 Patrick Meire ${ }^{2}$, Reinhart Ceulemans ${ }^{1}$, Ivan A. Janssens ${ }^{1}$

$8{ }^{1}$ Research Group of Plant and Vegetation Ecology, Department of Biology, University of Antwerp,

9 Universiteitsplein 1, B-2610 Wilrijk, Belgium

102 Ecosystem Management Research Group, Department of Biology, University of Antwerp,

11 Universiteitsplein 1, B-2610 Wilrijk, Belgium

14 Number of text pages: 13

15 Number of figures: 3

16 Number of tables: 2

18 Corresponding author: Sara Vicca

Fax: +3238202272

* Correspondence address: Sara Vicca, Universiteitsplein 1, 2610 Wilrijk, Belgium 


\section{Abstract}

25 In a mesocosm experiment, with bare peat soils exposed to different water levels

26 (WL), we examined whether heterotrophic respiration $\left(\mathrm{R}_{\mathrm{h}}\right)$ acclimated to a $3{ }^{\circ} \mathrm{C}$

27 temperature increase. Across all WLs, $\mathrm{R}_{\mathrm{h}}$ at $15{ }^{\circ} \mathrm{C}$ was never lower in the heated

28 treatment than in the unheated treatment, indicating that $\mathrm{R}_{\mathrm{h}}$ did not acclimate to the

29 warmer conditions. We hypothesize that this lack of thermal acclimation is due to the

30 unlimited substrate availability in these organic soils. These results imply that peat soils

31 may exhibit a sustained positive feedback to global warming.

32

33 Keywords: Heterotrophic respiration; Peat soil; Thermal acclimation; Warming; Substrate

34 depletion 
In mineral soils, warming-induced increases in soil respiration $\left(\mathrm{R}_{\text {soil }}\right)$ are often

36 restricted to the early stages of heating experiments, after which $\mathrm{R}_{\text {soil }}$ frequently returns to

37 its original level (Hyvönen et al., 2007). Possible mechanisms for such thermal

38 acclimation are (i) physiological adaptations of soil microorganisms (e.g., shifts in

39 temperature optima), (ii) shifts in microbial community structure towards species with

40 higher temperature optima, and (iii) labile substrate depletion. Whereas the importance of

41 the first two mechanisms is still under debate, modeling studies (Kirschbaum, 2004;

42 Eliasson et al., 2005) demonstrated that depletion of labile substrates is very likely to play

43 a key role.

44 Peat soils, on the other hand, store enormous amounts of carbon (Gorham et al.,

45 1991) of which a large fraction is relatively labile. Hence, depletion of easily degradable

46 organic matter is less likely in these soils. If substrate limitation is indeed the main causal

47 mechanism for thermal acclimation, $\mathbf{R}_{\text {soil }}$ in organic soils may thus not acclimate to

48 warming. To our knowledge, acclimation of $\mathrm{R}_{\text {soil }}$ to altered temperature regimes has not

49 yet been demonstrated in peat soils, but was so far assessed only in one study (Hartley et

50 al., 2008). Nonetheless, a sustained positive warming effect on $R_{\text {soil }}$ could have important

51 implications on climate change feedbacks, in particular because peat soils comprise up to

$5224 \%$ of global soil carbon stocks (Maltby and Immirzi, 1993). Moreover, if $\mathrm{R}_{\text {soil }}$ shows no

53 thermal acclimation in organic soils, this could imply that in mineral soils substrate

54 depletion is indeed the main driver for thermal acclimation of $\mathbf{R}_{\text {soil }}$.

55 In a mesocosm experiment, we exposed peat soils to two temperature regimes and

56 hypothesized that heterotrophic respiration $\left(\mathrm{R}_{\mathrm{h}}\right.$; the component of $\mathrm{R}_{\text {soil }}$ that is potentially

57 affected by depletion of labile carbon) did not acclimate to elevated temperatures. 
58 Because hydrology plays a key role in determining $\mathrm{CO}_{2}$ emissions from hydromorphic

59 soils (e.g., Jungkunst et al., 2008), we examined whether water level (WL) influenced

60 thermal acclimation of $R_{h}$.

61 In August 2006, an experimental platform was established at the University of

62 Antwerp. Three mesocosms (58 cm x $48 \mathrm{~cm}, 31 \mathrm{~cm}$ high) in each of six greenhouses

63 contained fen peat from nature reserve 'Het Wik' (Genk, Belgium; 50 57' N, $5^{\circ} 25^{\prime} \mathrm{E}$;

64 see Table 1 for soil characteristics) that was homogenized by hand to overcome

65 variability among mesocosms.. The peat was excavated from the top $50 \mathrm{~cm}$ and

66 aboveground plant parts (mainly Erica cinerea, Pieris sp. and Sphagnum sp.) were

67 removed. One PVC collar $(10 \mathrm{~cm}$ diameter $)$ was inserted in the middle of each

68 mesocosm. Before and in between measurements, mesocosms were darkened with

69 aluminum foil to avoid plant growth. After a 20 month equilibration period - during

70 which all mesocosms were exposed to ambient temperatures and a $\mathrm{WL}$ of $10 \mathrm{~cm}$ below

71 the surface - WLs and air temperatures were altered. From April 2008 on, WLs were set

72 at 5,10 , and $17 \mathrm{~cm}$ below the surface, with the three WLs randomly positioned in each

73 greenhouse. Water levels were controlled via the principle of communicating vessels.

74 One side of each mescosm was connected to a large vessel filled with rain water. At the

75 other side of the mesocosm, an outlet tube was set at the desired height, such that excess

76 water could drain from the mesocosm. Moreover, we controlled WLs three times per

77 week and made slight adjustments whenever necessary. Air temperatures in the

78 greenhouses were unaltered (unheated treatment) or increased by $3{ }^{\circ} \mathrm{C}$ relative to the

79 unheated treatment (heated treatment; three greenhouses per temperature treatment). The

80 experiment contained three replicates per treatment. 
82 times in each mesocosm by fitting a PVC headspace on the PVC collars. The headspace

83 (height: $9.5 \mathrm{~cm}$ ) was connected to a 1.11 bottle and an air pump that circulated air

84 between bottle and headspace. Via a septum in the headspace, six air samples were taken

85 within $20 \mathrm{~min}$ after enclosure. Samples, collected in $20 \mathrm{ml}$ vacuum vials, were analyzed

86 for $\mathrm{CO}_{2}$ concentrations with a gas chromatograph equipped with a ${ }^{63} \mathrm{Ni}$ electron capture

87 detector (Trace GC Ultra, Thermo Electron S.p.A., Milan, Italy). A calibration gas

88 (1612 ppm $\mathrm{CO}_{2}$ ) was measured at regular intervals. We calculated $\mathrm{R}_{\mathrm{h}}$ as the slope of the

89 linear regression fitted to the data (concentration versus time). In the rare case where we

90 observed an indication of saturation, only the first four data points were used (which

91 never showed any sign of saturation).

92 Besides $\mathrm{CO}_{2}$ fluxes, we also measured soil water content (SWC) and $\mathrm{O}_{2}$

93 concentrations at different soil depths. We measured SWC with a PR2 soil probe (Delta-

94 T Devices Ltd., UK) utilizing the profile probe tube (554 $\mathrm{mm}$ length) that installed in

95 each mesocosm. Oxygen concentrations were measured using $\mathrm{O}_{2}$ optrodes (PreSens

$96 \mathrm{GmbH}$, Regensburg, Germany). Small round pieces (4 mm diameter) of $\mathrm{O}_{2}$ sensitive foil

97 were fixed on the dead end of a glass pipe. These glass pipes were permanently installed

98 at the desired depth (above and below the WL; see also Table 2). For $\mathrm{O}_{2}$ determination, a

99 polymer optical fiber, connected to an $\mathrm{O}_{2}$ meter, was inserted in the glass pipe.

100 To obtain a sufficiently large temperature range, with overlaps between the 101 treatments, air temperatures were altered several times during the measurement period 102 (Fig. 1). This resulted in flux measurements covering soil temperatures (at $5 \mathrm{~cm} \mathrm{depth)}$ 103 between 9 and $22{ }^{\circ} \mathrm{C}$. Subsequently, we fitted Eq. 1 to the data to compute basal 
104 respiration $(\mathrm{BR})$ at one reference temperature $\left(15^{\circ} \mathrm{C}\right)$ for all mesocosms (regressions 105 were fitted in Matlab; 7.2.0.232, The Mathworks, US).

$106 \mathrm{R}_{\mathrm{h}}=\mathrm{BR} * \mathrm{Q}_{10}{ }^{((\mathrm{T} s-15) / 10)}$

107 with $\mathrm{T}_{\mathrm{S}}$ the soil temperature at $5 \mathrm{~cm}$ depth and $\mathrm{Q}_{10}$ the temperature sensitivity. Thermal 108 acclimation would result in a lower BR in the heated versus the unheated treatment.

109 We calculated the weighted mean BR for each treatment using the inverse of the 110 standard error of BR as weight factor. A weighted ANCOVA (Analysis of Covariance),

111 with WL as covariate and temperature (T) treatment as a fixed factor, was used to test for

$112 \mathrm{WL}$ and $\mathrm{T}$ effects and for WL $\mathrm{x} T$ interactions. Statistical analyses were performed in 113 SAS (SAS system 9.1, SAS Institute, Cary, NC, USA).

114 In agreement with other studies on organic soils (e.g., Moore and Dalva, 1997; Jungkunst 115 et al., 2008), $R_{h}$ increased with increasing depth of water level $(p=0.10$; Fig. 2). We 116 further observed that $\mathrm{R}_{\mathrm{h}}$ showed similar BRs in heated and unheated mesocosms, for all 117 WLs (T effect: $\mathrm{p}=0.84$; WL $\mathrm{x}$ T interaction: $\mathrm{p}=0.97$; Fig. 2). Hence, we did not detect 118 any sign of thermal acclimation. Even relative to pretreatment measurements, no 119 indication of thermal acclimation was apparent; in contrast, at the two higher WLs, 120 increases in BR accompanied the heated treatment (Fig. 2). Neither SWC, nor $\mathrm{O}_{2}$ 121 concentration can be responsible for the lack of acclimation, as both parameters were 122 similar in heated and unheated mesocosms (Fig. 3 and Table 2).

123 Our results confirm the only other study on organic soils (Hartley et al., 2008), which 124 also found no thermal acclimation of $\mathrm{R}_{\mathrm{h}}$ following temperature manipulation. This lack of 125 thermal acclimation contrasts with observations in mineral soils, where temperature126 induced reductions of $R_{h}$ are frequently detected (Luo et al., 2001; Melillo et al., 2002; 
127 Hyvönen et al 2007). As was demonstrated via modeling (Kirschbaum, 2004; Eliasson et

128 al., 2005), and recently also experimentally (Bradford et al., 2008), substrate limitation

129 could be an important mechanism underlying the thermal acclimation of $\mathrm{R}_{\mathrm{h}}$. The lack of

130 any indication of a lower BR in heated versus unheated soils might thus be taken to

131 suggest that warming did not induce substrate depletion in our experiment, not even at

$132 \mathrm{WL}=-5 \mathrm{~cm}$, where the aerobic zone of $\mathrm{CO}_{2}$ production was smallest.

133 In agreement with our results, Weintraub and Schimel (2003) found that, despite

134 considerable carbon losses, soil organic matter chemistry of different organic tundra soils

135 remained largely unchanged after one year incubation at room temperature. This

136 suggested that substrate availability did not limit microbial activity. Furthermore, an

137 incubation study where organic soils were exposed to different temperature and moisture 138 regimes also demonstrated that microbial respiration was not limited by carbon 139 availability (Shaver et al., 2006).

140 We thus conclude that we were not able to detect thermal acclimation of 141 heterotrophic respiration. If this would be a general response, global warming could 142 generate a persistent positive climate feedback in peatland ecosystems.

\section{Acknowledgements}

146 We thank Marc Fourier, custodian of nature reserve 'Het Wik', for the peat soil of this

147 nature reserve. We thank Wout Opdekamp, Bert Gielen, Stefanie De Rocker and Marilyn

148 Roland for very useful help with the field experiments. We also thank two anonymous

149 reviewers for their constructive review. Sara Vicca holds a grant from the Institute for 
150 Promotion of Innovation through Science and Technology in Flanders (IWT-

151 Vlaanderen). Lise Fivez holds a Ph.D. fellowship of the Research Foundation - Flanders 152 (FWO). 


\section{References}

155 Bradford, M.A., Davies, C.A., Frey, S.D., Maddox, T.R., Melillo, J.M., Mohan, J.E.,

156 Reynolds, J.F., Treseder, K.K., Wallenstein, M.D., 2008. Thermal adaptation of soil

157 microbial respiration to elevated temperature. Ecology Letters 11, 1316-1327.

158

159 Eliasson, P.E., McMurtrie, R.E., Pepper, D.A., Strömgren, M., Linder, S., Agren, G.I., 160 2005. The response of heterotrophic $\mathrm{CO}_{2}$ flux to soil warming. Global Change Biology 161 11, 167-181.

163 Gorham, E., 1991. Northern peatlands: role in the carbon cycle and probable responses to 164 climatic warming. Ecological Applications 1, 182-195.

166 Hartley, I.P., Hopkins, D.W., Garnett, M.H., Sommerkorn, M., Wookey, P.A., 2008. Soil

167 microbial respiration in arctic soil does not acclimate to temperature. Ecology letters 11, 168 1092-1100.

170 Hyvönen, R., Ågren, G.I., Linder, S., Persson, T., Cotrufo, M.F., Ekblad, A., Freeman, 171 M., Grelle, A., Janssens, I.A., Jarvis, P.G., Kellomäki, S., Lindroth, A., Loustau, D., 172 Lundmark, T., Norby, R.J., Oren, R., Pilegaard, K., Ryan, M.G., Sigurdsson, B.D., 173 Strömgren, M., van Oijen, M., Wallin, G., 2007. The likely impact of elevated $\left[\mathrm{CO}_{2}\right]$, 174 nitrogen deposition, increased temperature and management on carbon sequestration in 
175 temperate and boreal forest ecosystems: a literature review. New Phytologist 173, 463-

176480.

177

178 Jungkunst, H.F., Flessa, H., Scherber, C., Fiedler, S., 2008. Groundwater level controls

$179 \mathrm{CO}_{2}, \mathrm{~N}_{2} \mathrm{O}$ and $\mathrm{CH}_{4}$ fluxes of three different hydromorphic soil types of a temperate forest

180 ecosystem. Soil Biology and Biochemistry 40, 2047-2054.

181

182 Kirschbaum, M.U.F., 2004. Soil respiration under prolonged soil warming: are rate 183 reductions caused by acclimation or substrate loss? Global Change Biology 10, 18701841877.

185

186 Luo, Y., Wan, S., Hui, D., Wallace, L.L., 2001. Acclimatization of soil respiration to 187 warming in a tall grass prairie. Nature 413, 622-625.

188

189 Maltby, E., Immirzi, P., 1993. Carbon dynamics in peatlands and other wetland soils 190 regional and global perspectives. Chemosphere 27, 999-1023.

191

192 Melillo, J.M., Steudler, P.A., Aber, J.D., Newkirk, K., Lux, H., Bowles, F.P., Catricala, 193 C., Magill, A., Ahrens, T., Morrisseau, S., 2002. Soil warming and carbon-cycle 194 feedbacks to the climate system. Science 298, 2173-2176.

195 
196 Moore, T.R., Dalva, M., 1997. Methane and carbon dioxide exchange potentials of peat

197 soils in aerobic and anaerobic laboratory incubations. Soil Biology and Biochemistry 29, $198 \quad 1157-1164$.

199

200 Shaver, G.R., Giblin, A.E., Nadelhoffer, K.J., Thieler, K.K., Downs, M.R., Laundre, J.A.,

201 Rastetter, E.B., 2006. Carbon turnover in Alaskan tundra soils: effects of organic matter

202 quality, temperature, moisture and fertilizer. Journal of Ecology 94, 740-753.

203

204 Weintraub, M.N., Schimel, J.P., 2003. Interactions between carbon and nitrogen 205 mineralization and soil organic matter chemistry in arctic tundra soils. Ecosystems 6, 206 129-143. 
209 Table 1: Initial soil characteristics.

\begin{tabular}{cccccc}
\hline $\begin{array}{c}\text { Bulk density } \\
\left(\mathrm{g} \mathrm{cm}^{-3}\right)\end{array}$ & $\begin{array}{c}\text { Organic matter } \\
\left(\% \text { loss of ignition at } 105{ }^{\circ} \mathrm{C}\right)\end{array}$ & $\begin{array}{c}\text { C content } \\
(\%)\end{array}$ & $\begin{array}{c}\mathbf{N} \text { content } \\
(\%)\end{array}$ & $\mathbf{C} / \mathbf{N}$ pH \\
\hline 0.012 & 72.4 & 44.2 & 2.2 & 20 & 6.6 \\
\hline
\end{tabular}

212 Table 2: Mean $\mathrm{O}_{2}$ concentration (\% of air saturation) measured at different soil depths

213 and the standard deviation on the mean (SD) for the two temperature treatments at the

214 three water levels (WL) $(\mathrm{n}=3)$.

\begin{tabular}{|c|c|c|c|c|c|c|c|c|c|c|c|c|}
\hline & \multicolumn{4}{|c|}{$W L=-5 \mathrm{~cm}$} & \multicolumn{4}{|c|}{$W L=-10 \mathrm{~cm}$} & \multicolumn{4}{|c|}{$\mathrm{WL}=-17 \mathrm{~cm}$} \\
\hline & \multicolumn{2}{|c|}{ unheated } & \multicolumn{2}{|c|}{ heated } & \multicolumn{2}{|c|}{ unheated } & \multicolumn{2}{|c|}{ heated } & \multicolumn{2}{|c|}{ unheated } & \multicolumn{2}{|c|}{ heated } \\
\hline Depth & Mean & SD & Mean & SD & Mean & SD & Mean & SD & Mean & SD & Mean & SD \\
\hline$-4 \mathrm{~cm}$ & 48.3 & 42.0 & 46.7 & 40.8 & 71.1 & 0.4 & 70.8 & 7.6 & 70.7 & 0.9 & 69.1 & 10.0 \\
\hline$-6 \mathrm{~cm}$ & 0.0 & 0.0 & 0.0 & 0.0 & 1 & 1 & 1 & 1 & 1 & 1 & 1 & 1 \\
\hline$-10 \mathrm{~cm}$ & 1 & 1 & 1 & 1 & 1 & 1 & $\backslash$ & 1 & 71.7 & 1.9 & 71.5 & 8.2 \\
\hline$-12 \mathrm{~cm}$ & 1 & 1 & 1 & 1 & 0.0 & 0.0 & 0.0 & 0.0 & 1 & 1 & 1 & 1 \\
\hline$-18 \mathrm{~cm}$ & 1 & 1 & 1 & 1 & 1 & 1 & 1 & 1 & 0.0 & 0.0 & 0.0 & 0.0 \\
\hline
\end{tabular}




\section{Figures}

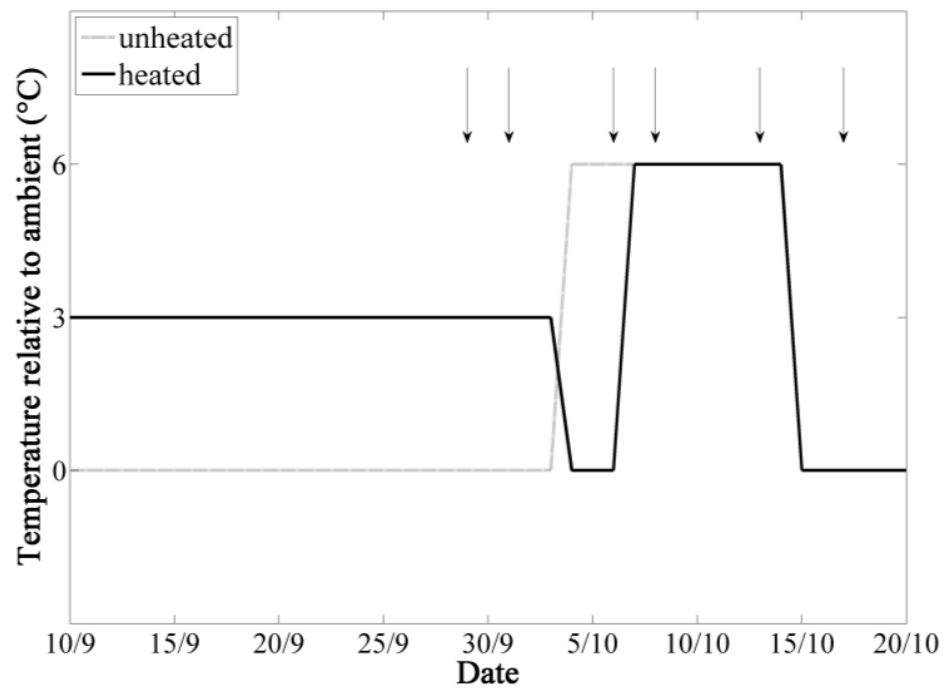

218 Figure 1: Adjustments of air temperatures in both temperature treatments just before and

219 during the period of gas flux measurements. Arrows indicate the measurement dates. 


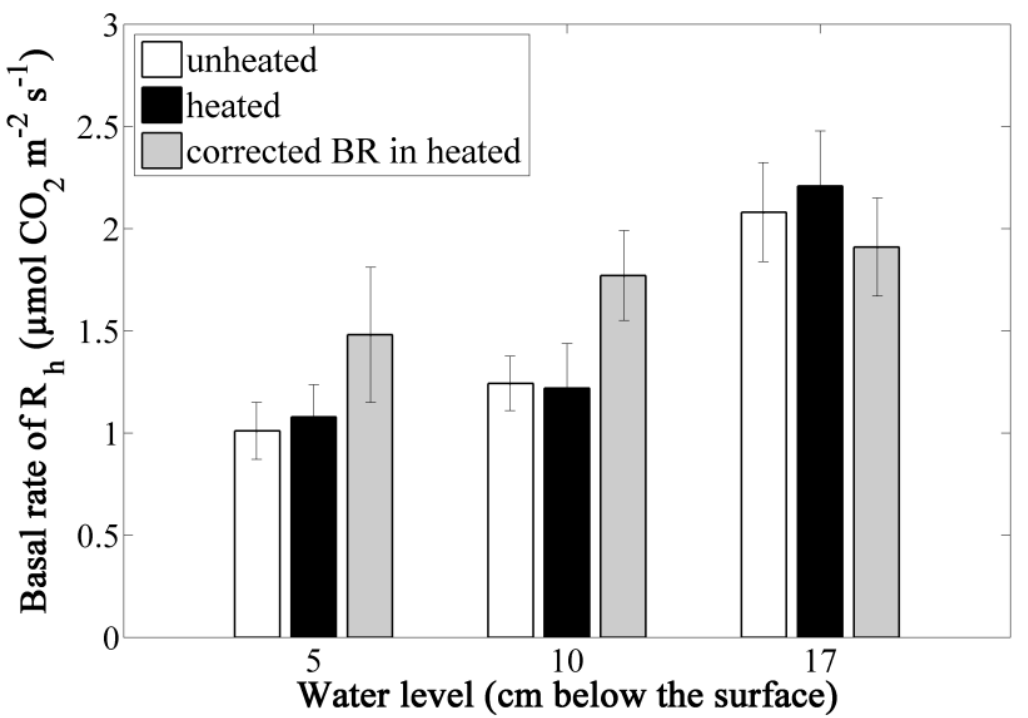

222 Figure 2: Weighted mean basal rate (BR; i.e., heterotrophic respiration $\left(\mathrm{R}_{\mathrm{h}}\right)$ at $\left.15^{\circ} \mathrm{C}\right)$ for 223 the two temperature treatments at the three water levels $(n=3)$. To ensure that the results 224 were not affected by pretreatment differences, we corrected the basal rates as follows: 225 corrected $\mathrm{BR}$ in heated $=\mathrm{BR}$ in heated $*(\mathrm{BR}$ pretreatment in unheated/BR pretreatment 226 in heated). Error bars represent one standard error on the weighted mean. 
Depth 1

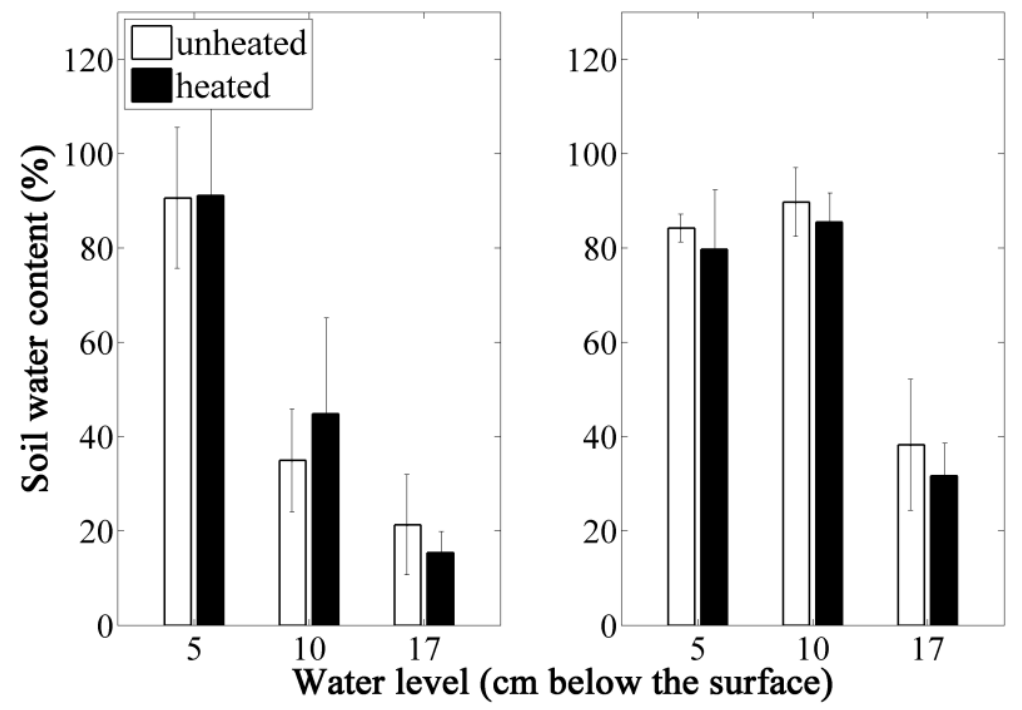

Depth 2
229 Figure 3: Mean soil water content for the two temperature treatments at the three water 230 levels $(\mathrm{n}=3)$. Soil water content was measured between 5 and $15 \mathrm{~cm}$ depth (depth 1$)$ and 231 between 10 and $20 \mathrm{~cm}$ depth (depth 2). Error bars present the standard deviation on the 232 mean. 